\title{
Pesquisas sobre professores e sua formação: uma análise de pesquisas desenvolvidas no programa de Pós- Graduação da FEUSP - 1990 a 1998
}

\section{Research on teachers and teacher education: an analysis of research developed in the graduate programme of education at FEUSP covering the years from 1990 to 1998}

\author{
Selma Garrido Pimenta* \\ Verbena Moreira Soares de Sousa Lisita**
}

\begin{abstract}
RESUMO
O trabalho apresenta uma análise das teses e dissertações sobre temas correlacionados à formação de professores na FEUSP no período de 1990 a 1998. Seu objetivo é o de sistematizar as contribuições de pesquisas desenvolvidas no programa de pós-graduação em educação da FEUSP sobre temáticas relacionadas à formação de professores e estudos sobre o professor. Como fonte para o levantamento de dados foi utilizado o Catálogo de teses e dissertações defendidas na FEUSP - 1967 a 1998, contendo os resumos de 788 teses e dissertações, dentre as quais foram analisadas 87 pesquisas, selecionadas dentre 549 resumos referentes ao período de interesse. Baseado nessas análises, o estudo apresenta uma síntese das contribuições dessas pesquisas para o campo da Didática, disciplina da qual as autoras são professoras em cursos de formação de professores. Importante informar que o presente trabalho faz parte de um estudo maior, intitulado As pesquisas sobre temas correlacionados ao ensino e à for-
\end{abstract}

* Professora doutora da Universidade de São Paulo. E-mail: sgpiment@usp.br

** Doutoranda da Universidade de São Paulo. E-mail: lisita@uol.com.br 
mação de professores na FEUSP-1990 a 1998, cujo objetivo é sistematizar as contribuições de pesquisas desenvolvidas no programa de Pós-Graduação em educação da FEUSP sobre temáticas relacionadas a problemas e preocupações da didática: o ensino e a formação de professores.

Palavras-chave: formação de professores, didática, ensino, pesquisas.

\begin{abstract}
This study presents an analysis of theses and dissertations on themes related to teacher education in FEUSP from 1990 to 1998. The aim of the study is to systematise researches on teachers and teacher education, developed in the Graduate Programme of Education at FEUSP. The source of the data was a catalogue of theses and dissertations presented at FEUSP from 1967 to 1998 , which contains 788 abstracts of theses and dissertations. Out of 549 abstracts referring to the period of interest, 87 were selected to be analysed. Based on these analyses, the study presents a summary of the contributions of these researches to the field of didactics. This study is part of a broader investigation, entitled researches on themes related to teaching and teacher education at FEUSP - from 1990 to 1998, whose aim is to systematize the contributions of researches developed in the Graduate Programme of Education at FEUSP about problems and concerns of didactics: teaching and teacher education.
\end{abstract}

Key-words: teacher education, didactics, teaching, research.

\title{
Introdução
}

O texto apresenta uma análise das teses e dissertações sobre temas relacionados à formação de professores defendidas no programa de Pós-Graduação em Educação da FEUSP, no período de 1990 a 1998. Seu objetivo é o de sistematizar e analisar as contribuições das pesquisas à compreensão de problemas e preocupações da didática sobre os professores e sua formação ${ }^{1}$.

${ }^{1} \mathrm{O}$ trabalho apresenta os resultados parciais da investigação As pesquisas sobre ensino $e$ formação de professores, defendidas no programa de Pós-Graduação da FEUSP-1990 a 1998, cujo objetivo é o de sistematizar e analisar as contribuições que apresentam ao ensino e à formação de professores, temáticas centrais da didática. 
O interesse em realizar o estudo está relacionado à natureza das preocupações da didática como campo de conhecimento cujo objeto de estudo é o ensino como prática social. Está relacionado, também, aos desafios teóricos e práticos que a didática necessita enfrentar para contribuir para a formação de professores na sua especificidade, que é o ensinar a ensinar.

Um desses desafios é o de compreender por quais processos se pode auxiliar os professores em formação a compreender e a realizar o ensino. Assim, no presente estudo se indaga: quais as contribuições das pesquisas para a produção do conhecimento sobre os professores e a sua formação? É possível firmar consensos provisórios sobre o tema da formação docente tendo como referência as pesquisas analisadas? E quanto ao que ainda não se sabe, que aspectos estariam a merecer novas pesquisas? Essas e outras questões poderão contribuir para a melhoria da qualidade da formação docente e do ensino.

A fonte para o levantamento de dados foi o Catálogo de Teses e Dissertações defendidas na FEUSP - 1967 a 1998, lançado em dezembro de 2002, contendo os resumos de 788 teses e dissertações defendidas no programa nesse período ${ }^{2}$. Para sua realização, procedeu-se a uma leitura inicial de 549 resumos referentes ao período de 1990 a 1998, a fim de se identificar as pesquisas que versavam sobre os temas de interesse. Nas tabelas a seguir, visualizase a distribuição desse conjunto no período.

TABELA 1 - DISTRIBUIÇÃO QUANTITATIVA DE TESES E DISSERTAÇÕES DEFENDIDAS NA FEUSP NO PERÍODO DE 1990 A 1998

\begin{tabular}{|l|l|l|l|l|l|l|l|l|l|l|}
\hline Tipo/ano & $\mathbf{1 9 9 0}$ & $\mathbf{1 9 9 1}$ & $\mathbf{1 9 9 2}$ & $\mathbf{1 9 9 3}$ & $\mathbf{1 9 9 4}$ & $\mathbf{1 9 9 5}$ & $\mathbf{1 9 9 6}$ & $\mathbf{1 9 9 7}$ & $\mathbf{1 9 9 8}$ & Totais \\
\hline Mestrado & 13 & 20 & 13 & 13 & 24 & 38 & 54 & 43 & 33 & $\mathbf{2 5 1}$ \\
\hline Doutorado & 12 & 12 & 17 & 23 & 34 & 40 & 36 & 47 & 45 & $\mathbf{2 6 6}$ \\
\hline $\begin{array}{l}\text { Livre- } \\
\text { Docência }\end{array}$ & 06 & 03 & 03 & 04 & 07 & 05 & 03 & 01 & ---- & $\mathbf{3 2}$ \\
\hline Total & $\mathbf{3 1}$ & $\mathbf{3 5}$ & $\mathbf{3 3}$ & $\mathbf{4 0}$ & $\mathbf{6 5}$ & $\mathbf{8 3}$ & $\mathbf{9 3}$ & $\mathbf{9 1}$ & $\mathbf{7 8}$ & $\mathbf{5 4 9}$ \\
\hline
\end{tabular}

${ }^{2}$ A década de 1990 foi escolhida por representar uma virada na pesquisa educacional em todo o mundo, tendo por foco os professores e sua formação. Além disso, nesse período, as pesquisas sobre o tema passaram a representar número significativo no programa de Pós-Graduação da FEUSP em relação ao conjunto de teses e dissertações defendidas desde a sua criação.

O volume Resumos de teses e dissertações defendidas na FEUSP - 1999 - 2003 encontrase em elaboração, devendo constituir objeto de novo estudo. 
Desse total, 282 pesquisas foram identificadas com temas correlacionados à formação de professores (87) e ao ensino (195). Foram consideradas como pesquisas sobre formação de professores (43) aquelas que indicaram explicitamente versarem sobre essa temática e os estudos sobre o professor (44), por apresentarem elementos que auxiliam na compreensão de processos de formação de professores.

Entre as pesquisas sobre temas correlacionados ao ensino, foram identificadas 92 que tratavam especificamente de problemas relacionados ao ensino de uma disciplina, e 103 que, de alguma forma, tratavam de problemas que atravessam o trabalho docente com o conhecimento em situações de ensino e aprendizagem.

O presente estudo contempla somente o exame do primeiro grupo de pesquisas, ou seja, as correlacionadas à formação de professores e os estudos sobre o professor $(87)^{3}$.

TABELA 2 - PESQUISAS SOBRE TEMAS CORRELACIONADOS À FORMAÇÃO DE PROFESSORES E AO ENSINO CONFORME TIPO DE ESTUDO (MESTRADO, DOUTORADO E LIVREDOCÊNCIA)

\begin{tabular}{|l|l|l|l|l|l|}
\hline Temáticas de interesse dos estudos & Mestrado & Doutorado & $\begin{array}{l}\text { Livre- } \\
\text { docência }\end{array}$ & Total & $\begin{array}{l}\text { Análises } \\
\text { nos } \\
\text { quadros }\end{array}$ \\
\hline Formação de professores & 13 & 28 & 02 & 43 & I \\
\hline Estudos sobre o professor & 20 & 21 & 03 & 44 & II \\
\hline Ensino de uma disciplina & 44 & 47 & 01 & 92 & \\
\hline $\begin{array}{l}\text { Problemas que atravessam o trabalho } \\
\text { docente com o conhecimento em } \\
\text { situações de ensino e aprendizagem }\end{array}$ & 50 & 47 & 06 & 103 & \\
\hline
\end{tabular}

Para realizar a análise das pesquisas foram consideradas as seguintes categorias: locus da formação; temas; subtemas, conteúdos e propósitos; metodologias ou procedimentos; e resultados ou conclusões. Essas mesmas categorias foram observadas para os estudos sobre o professor, exceto a primeira, por não ter sido mencionada em grande parte dos resumos. A sistematização dessas categorias encontra-se nos quadros I e II e constituem a base para a análise a seguir. Considerando as limitações da fonte de dados utilizada, não foi possível discutir as referências teóricas e os resultados das pesquisas.

${ }^{3}$ A tabela II apresenta a distribuição do total dessas pesquisas conforme sua origem: mestrado, doutorado e livre-docência. 


\section{As pesquisas sobre formação de professores}

Examinando-se o quadro I, identifica-se quanto ao locus de formação que 12 pesquisas referem-se a licenciaturas, 14 à formação contínua, 12 à escola normal e ao Centro de Formação e Aperfeiçoamento do Magistério $(\text { Cefam })^{4}, 3$ à pedagogia e 4 à formação do professor do ensino superior.

QUADRO I - PESQUISAS SOBRE FORMAÇÃO DE PROFESSORES E ESTUDOS SOBRE O PROFESSOR - 1990-1998 (43 PESQUISAS)

\begin{tabular}{|c|c|c|c|}
\hline $\begin{array}{l}\text { Locus da } \\
\text { formação }\end{array}$ & $\begin{array}{l}\text { Temas/Subtemas/Con- } \\
\text { teúdos/Propósitos }\end{array}$ & $\begin{array}{l}\text { Metodologia/ } \\
\text { Procedimentos }\end{array}$ & Resultados/Conclusões \\
\hline $\begin{array}{l}\text { Licenciatu- } \\
\text { ra } \\
\text { Doutorado } \\
\text { (12) }\end{array}$ & $\begin{array}{l}\text {-Investigações sobre: 1) } \\
\text { aprendizagem por mudan- } \\
\text { ça conceitual na perspec- } \\
\text { tiva do professor como } \\
\text { prático reflexivo na disci- } \\
\text { plina prática de ensino de } \\
\text { ciências; } 2 \text { ) evolução das } \\
\text { concepções sobre ensino e } \\
\text { aprendizagem e prática na } \\
\text { disciplina prática de ensi- } \\
\text { no de física; } \\
\text {-Estudo da trajetória da } \\
\text { disciplina prática de en- } \\
\text { sino de inglês; } \\
\text {-Análise da contribuição } \\
\text { da reflexão distanciada na } \\
\text { aprendizagem da docência } \\
\text { no contexto de disciplina } \\
\text { de caráter teórico-meto- } \\
\text { dológico; } \\
\text {-Estudo sobre o papel da } \\
\text { pesquisa-ação como alter- } \\
\text { nativa metodológica de } \\
\text { aprendizagem da docência }\end{array}$ & $\begin{array}{l}\text {-Análise de situações re- } \\
\text { ais de aprendizagem da } \\
\text { docência/disciplina prá- } \\
\text { tica de ensino (2); } \\
\text {-Estudo de um caso (2); } \\
\text {-Levantamento/depoi- } \\
\text { mentos e análise docu- } \\
\text { mental (1); } \\
\text {-Pesquisa teórica (1); } \\
\text {-Análise documental (1); } \\
\text {-Pesquisa-ação (1); } \\
\text {-Sem informações sufici- } \\
\text { entes sobre metodologia } \\
\text { (4); }\end{array}$ & $\begin{array}{l}\text {-Confirmação de processos de } \\
\text { mudança conceitual dos futuros } \\
\text { professores em situações reais de } \\
\text { ensino; } \\
\text {-Reflexão sobre } 3 \text { modelos de for- } \\
\text { mação (de ofício, da ciência apli- } \\
\text { cada e reflexivo); } \\
\text {-Defesa da reflexão distanciada } \\
\text { como componente essencial da } \\
\text { construção de conhecimentos } \\
\text { profissionais do professor; } \\
\text {-Apresentação de elementos teó- } \\
\text { ricos para a formação do profes- } \\
\text { sor na perspectiva histórico-cultu- } \\
\text { ral (MARX, GRAMSCI e vYGOTSKY); } \\
\text {-Apresentação de subsídios para } \\
\text { o aperfeiçoamento da disciplina } \\
\text { prática de ensino de Geografia; } \\
\text {-Apresentação de sugestão para } \\
\text { retomar os objetivos do colégio } \\
\text { de aplicação; } \\
\text {-Identificação de aprendizagens } \\
\text { profissionais resultantes de proces- } \\
\text { so de pesquisa-ação colaborativa; }\end{array}$ \\
\hline
\end{tabular}

${ }^{4} \mathrm{O}$ projeto Cefam, foi concebido como alternativa pedagógica ao redimensionamento da Escola Normal (Habilitação Magistério), no início dos anos 1980. É uma proposta político-pedagógica que nasceu sob a égide da participação e da responsabilidade compartida (governos federal e estaduais) e que se desenvolveu em alguns estados, com a colaboração financeira do MEC, ou com recursos do próprio estado, como no caso de São Paulo, onde foram implantados 54 Cefams, que funcionaram até 2003. (cf. PIMENTA, S. G. O estágio na formação de professores: unidade teoria - prática? São Paulo: Cortez, 1991). 


\begin{tabular}{|c|c|c|c|}
\hline & $\begin{array}{l}\text { e parceria universidade/ } \\
\text { rede de ensino; } \\
\text {-Divulgação e aplicação de } \\
\text { proposta de ensino de ciên- } \\
\text { cias para as séries iniciais; } \\
\text {-Apresentação de elemen- } \\
\text { tos teóricos para a forma- } \\
\text { ção do professor na pers- } \\
\text { pectiva histórico cultural } \\
\text { (MARX, GRAMSCI } \\
\text { vYGOTSKY); } \\
\text {-Apresentação de subsí- } \\
\text { dios para o aperfeiçoa- } \\
\text { mento da disciplina práti- } \\
\text { ca de ensino de Geografia; } \\
\text {-Relato de experiência do } \\
\text { colégio de aplicação na } \\
\text { formação de professores } \\
\text { de francês; } \\
\text {-Avaliação das relações } \\
\text { ciência/tecnologia/socie- } \\
\text { dade nas mudanças curri- } \\
\text { culares e na formação de } \\
\text { professores; } \\
\text {-Avaliação da formação } \\
\text { proporcionada pela licen- } \\
\text { ciatura em Matemática; } \\
\text {-Estudo da relação teoria- } \\
\text { prática na disciplina prá- } \\
\text { tica de ensino de História } \\
\text { e Ciências Sociais; }\end{array}$ & & $\begin{array}{l}\text {-Avaliação das relações ciência/ } \\
\text { tecnologia/sociedade nas mudan- } \\
\text { ças curriculares e na formação de } \\
\text { professores; } \\
\text {-Denúncia de problemas na for- } \\
\text { mação do licenciado em matemá- } \\
\text { tica (incompreensão da relação } \\
\text { teoria e prática, fragmentação da } \\
\text { formação etc). }\end{array}$ \\
\hline $\begin{array}{l}\text { Formação } \\
\text { contínua } \\
\\
\text { Mest. (3) } \\
\text { Dout. (7) } \\
\text { Liv.-Doc. } \\
\text { (1) } \\
\text { Total (11) }\end{array}$ & $\begin{array}{l}\text {-Estudo sobre a vivência } \\
\text { de um projeto de investi- } \\
\text { gação-ação, desenvolvido } \\
\text { por um grupo de professo- } \\
\text { res de Ciências Naturais; } \\
\text {-Caracterização de um } \\
\text { curso a distância para } \\
\text { mudar a prática docente; } \\
\text {-Análise de práticas docen- } \\
\text { tes com uso de novas tecno- } \\
\text { logias na universidade; } \\
\text {-Estudo das representa- } \\
\text { ções de coordenadores pe- } \\
\text { dagógicos sobre formação } \\
\text { contínua de educadores; } \\
\text {-Análise de projeto de for- } \\
\text { mação em serviço na } \\
\text { abordagem reflexiva; }\end{array}$ & $\begin{array}{l}\text {-Pesquisa-ação (2); } \\
\text {-Análise de cursos de } \\
\text { EaD (1); } \\
\text {-Análise de experiências } \\
\text { de formação (3); } \\
\text {-Levantamento/entrevis- } \\
\text { ta e análise de vídeogra- } \\
\text { vações de aulas (1); } \\
\text {-Pesquisa etnográfica } \\
\text { (1); } \\
\text {-Sem informações sufici- } \\
\text { entes sobre metodologia } \\
(3) ;\end{array}$ & \begin{tabular}{|}
-Possibilidade de reflexões/pro- \\
dução de conhecimento dos pro- \\
fessores sobre o ensino de Ciên- \\
cias Naturais; \\
-Conhecimento sobre o aprender \\
da profissão: o professor apren- \\
de a ser professor desde quando \\
ingressa na escola; o saber que o \\
professor constrói na formação é \\
ético e estético; \\
-Conhecimento sobre formação e \\
EaD: cursos estruturados em fun- \\
ção da lógica do conhecimento \\
sistematizado não bastam para \\
mudar a prática docente; é neces- \\
sário explicitar a relação teoria- \\
prática nesses cursos. Elaboração
\end{tabular} \\
\hline
\end{tabular}




\begin{tabular}{|c|c|c|c|}
\hline & $\begin{array}{l}\text {-Análise de curso de for- } \\
\text { mação contínua de pro- } \\
\text { fessores de educação in- } \\
\text { fantil com ênfase nos as- } \\
\text { pectos como motricidade, } \\
\text { afetividade, consciência } \\
\text { corporal etc; } \\
\text {-Análise da influência de } \\
\text { curso de atualização sobre } \\
\text { concepções de fazer ciên- } \\
\text { cia e ensinar ciência de } \\
\text { professores; } \\
\text {-Estudo sobre o jogo } \\
\text { como componente da for- } \\
\text { mação inicial e continua- } \\
\text { da de professores de edu- } \\
\text { cação especial; } \\
\text {-Estudo sobre formação } \\
\text { do professor leigo de cre- } \\
\text { ches como educador re- } \\
\text { flexivo; } \\
\text {-Estudo sobre práticas de } \\
\text { formação continuada para } \\
\text { a construção de novas re- } \\
\text { lações no cotidiano esco- } \\
\text { lar; } \\
\text {-Estudo da formação do } \\
\text { educador de creche na di- } \\
\text { nâmica do projeto educa- } \\
\text { cional; } \\
\text {-Estudo e acompanha- } \\
\text { mento de uma proposta } \\
\text { de aperfeiçoamento de } \\
\text { professores de Física ba- } \\
\text { seada em atividades } \\
\text { centradas na elaboração } \\
\text { de um planejamento } \\
\text { didático e na reflexão so- } \\
\text { bre a prática; }\end{array}$ & & $\begin{array}{l}\text { de um modelo de EaD para for- } \\
\text { mação de professores; } \\
\text {-Apresentação de um protótipo de } \\
\text { um sistema hipermídia de EaD; } \\
\text {-Conhecimento sobre formação } \\
\text { contínua: a) tendência de consi- } \\
\text { derar a formação como um } \\
\text { continnum; b) a escola como } \\
\text { locus privilegiado da formação; } \\
\text { c) o potencial da colaboração re- } \\
\text { flexiva na transformação da cul- } \\
\text { tura escolar; d) importância de se } \\
\text { considerar aspectos como motri- } \\
\text { cidade, consciência corporal, } \\
\text { afetividade etc. na formação de } \\
\text { professores de educação infantil; } \\
\text { e) importância de se compreen- } \\
\text { der a prática dos professores para } \\
\text { implementar processos de forma- } \\
\text { ção continuada; } \\
\text {-Conhecimento sobre formação } \\
\text { de professores para atuarna edu- } \\
\text { cação especial: a) uma escola } \\
\text { inclusiva requer uma nova peda- } \\
\text { gogia e novos professores; o co- } \\
\text { nhecimento das possibilidades do } \\
\text { jogo é fundamental na formação } \\
\text { de educadores; } \\
\text { Conhecimento sobreformação de } \\
\text { professores para educação infan- } \\
\text { til: a) potencial da abordagem re- } \\
\text { flexiva; b) importância de se con- } \\
\text { siderar o projeto educacional na } \\
\text { formação do educador de creche; } \\
\text { Conhecimento sobre formação } \\
\text { de professores e gênero: a pro- } \\
\text { dução sobre formação de profes- } \\
\text { sores (magistério) não considera } \\
\text { o referencial gênero; } \\
\text { - Conhecimento sobre papel dos } \\
\text { estágios: a) possibilidades da pes- } \\
\text { quisa acadêmica na transforma- } \\
\text { ção da prática; b) necessidade de } \\
\text { se acompanhar o estágio. }\end{array}$ \\
\hline $\begin{array}{l}\text { Escola } \\
\text { normal (7) }\end{array}$ & $\begin{array}{l}\text {-Estudo dos aspectos cul- } \\
\text { turais e do imaginário nas } \\
\text { práticas docentes; } \\
\text {-Estudos do aspecto gêne- } \\
\text { ro na formação de profes- } \\
\text { sores pelo magistério; }\end{array}$ & $\begin{array}{l}\text {-Análise documental (1); } \\
\text {-Pesquisa etnográfica } \\
(1) ; \\
\text {-Análise da prática peda- } \\
\text { gógica (2); }\end{array}$ & $\begin{array}{l}\text {-Reflexão sobre os aspectos cul- } \\
\text { turais e do imaginário nas práti- } \\
\text { cas docentes; } \\
\text { - Explicação histórica para a } \\
\text { feminilização do magistério; }\end{array}$ \\
\hline
\end{tabular}




\begin{tabular}{|c|c|c|c|}
\hline $\begin{array}{l}\text { Cefam (5) } \\
\text { Mest. (4) } \\
\text { Liv.-Doc. } \\
(1) \\
\text { Total (12) }\end{array}$ & $\begin{array}{l}\text {-Elaboração de proposta } \\
\text { de formação que conside- } \\
\text { ra a mediação docente no } \\
\text { desenvolvimento de uma } \\
\text { pedagogia crítica que in- } \\
\text { corpora as mídias; } \\
\text {-Caracterização do perfil } \\
\text { das alunas do curso de } \\
\text { Magistério; } \\
\text {-Estudo da aprendizagem } \\
\text { da leitura e da escrita na } \\
\text { disciplina Conteúdo e } \\
\text { Metodologia de Língua } \\
\text { Portuguesa do curso de } \\
\text { Magistério; } \\
\text {-Análise do projeto } \\
\text { Cefam e das dificuldades } \\
\text { de sua implantação; } \\
\text {-Estudo das dimensões } \\
\text { institucional, pedagógica, } \\
\text { histórica/filos ófica/ } \\
\text { epistemológica } \\
\text { Cefam; } \\
\text {-Estudo etnográfico sobre } \\
\text { significado da ação do- } \\
\text { cente entre professores do } \\
\text { magistério (Cefam); } \\
\text {-Estudos da prática de es- } \\
\text { tágio no Cefam (ênfase: } \\
\text { relação teoria e prática); }\end{array}$ & $\begin{array}{l}\text {-Análise da prática de } \\
\text { estágio de } 3 \text { estudantes } \\
\text { do Cefam (1); } \\
\text {-Levantamento/entrevis- } \\
\text { tas e observação (1); } \\
\text {-Levantamento/depoi- } \\
\text { mentos e análise docu- } \\
\text { mental (1); } \\
\text {-História Oral (1); } \\
\text {-Sem informações sufi- } \\
\text { cientes sobre metodo- } \\
\text { logia (4); }\end{array}$ & $\begin{array}{l}\text {-Conhecimento sobre mídias e } \\
\text { formação de professores: impor- } \\
\text { tância de se considerar a media- } \\
\text { ção docente na educação das cri- } \\
\text { anças em face às mídias; } \\
\text {-Presença/possibilidade da unida- } \\
\text { de entre teoria e prática nos } \\
\text { Cefams; }\end{array}$ \\
\hline $\begin{array}{l}\text { Pedagogia } \\
\text { Mest. (1) } \\
\text { Dout. (2) } \\
\text { Total (3) }\end{array}$ & $\begin{array}{l}\text {-Análise das vivências e } \\
\text { concepções das alunas; } \\
\text {-Estudo sobre a evolução } \\
\text { do curso de Pedagogia } \\
\text { como formador de profis- } \\
\text { sionais da educação; } \\
\text {-Estudo sobre as possibi- } \\
\text { lidades do pedagogo para } \\
\text { ensinar ciências nas séries } \\
\text { iniciais; }\end{array}$ & $\begin{array}{l}\text {-Levantamento/entrevis- } \\
\text { tas (1); } \\
\text {-Análise de experiência } \\
\text { (2); }\end{array}$ & $\begin{array}{l}\text {-Reflexão sobre a identidade so- } \\
\text { cial da mulher trabalhadora des- } \\
\text { de a antiguidade até os dias atuais } \\
\text { e importância do curso de Peda- } \\
\text { gogia na transformação da con- } \\
\text { dição social das alunas; } \\
\text {-Defesa de movimento nacional } \\
\text { em prol de uma política de for- } \\
\text { mação de educadores; } \\
\text {-Defesa da atuação do pedagogo } \\
\text { no ensino de ciências das séries } \\
\text { iniciais; }\end{array}$ \\
\hline $\begin{array}{l}\text { Formação } \\
\text { do Profes- } \\
\text { sor do ensi- } \\
\text { no superior } \\
\text { Dout. (5) }\end{array}$ & $\begin{array}{l}\text {-Estudos sobre a disci- } \\
\text { plina Metodologia do } \\
\text { Ensino Superior; } \\
\text {-Análise da prática do- } \\
\text { cente do professor de Fí- } \\
\text { sica do Ensino Superior; }\end{array}$ & $\begin{array}{l}\text {-Levantamento/entrevis- } \\
\text { tas, análise documental e } \\
\text { análise de experiência } \\
(1) ; \\
\text {-Análise de experiência } \\
\text { pedagógica (2); }\end{array}$ & $\begin{array}{l}\text {-Apesar de não possuir referencial } \\
\text { teórico próprio, a metodologia do } \\
\text { ensino superior pode se constituir } \\
\text { em campo específico de conheci- } \\
\text { mentos; } \\
\text {-Caracterização da prática docen- } \\
\text { te no ensino superior; }\end{array}$ \\
\hline
\end{tabular}




\begin{tabular}{|c|c|c|}
\hline $\begin{array}{l}\text {-Estudo sobre a transfor- } \\
\text { mação da memória dos } \\
\text { professores-alunos em sa- } \\
\text { beres necessários à práti- } \\
\text { ca de ensino universitário } \\
\text { (na disciplina Metodolo- } \\
\text { gia do Ensino Superior); } \\
\text { - Análise de prática do- } \\
\text { cente na universidade e } \\
\text { uso de novas tecnologias. }\end{array}$ & $\mid \begin{array}{l}\text {-Levantamento/entrevis- } \\
\text { ta e análise de prática } \\
\text { docente (1); }\end{array}$ & $\begin{array}{l}\text {-Fornecimento de subsídios para } \\
\text { a formação contínua de profes- } \\
\text { sores de Física e reconhecimento } \\
\text { do papel da prática reflexiva na } \\
\text { tomada de consciência do proces- } \\
\text { so de ensino e aprendizagem; } \\
\text { - Fornecimento de subsídios para } \\
\text { a reflexão sobre prática docente } \\
\text { na universidade a partir de um } \\
\text { protótipo parcial de um sistema } \\
\text { de educação a distância; }\end{array}$ \\
\hline
\end{tabular}

No primeiro grupo, encontram-se os estudos que analisam problemas da formação do professor em cursos de graduação nas universidades. No segundo, estão reunidas as pesquisas que abordam questões da formação de professores em serviço. O terceiro contempla as pesquisas sobre formação inicial do professor em cursos de nível médio e também em serviço, como é o caso dos trabalhos sobre os Cefams. Os dois últimos conjuntos de estudos tratam de questões específicas da pedagogia e da formação para o exercício da docência universitária. ${ }^{5}$

Nas pesquisas sobre as licenciaturas (12), verifica-se um enfoque em temas e questões específicas da disciplina de ensino para o qual o curso forma (ensino de ciências, física, inglês, geografia, francês, matemática etc). Seus autores são, geralmente, professores das disciplinas de prática de ensino desses cursos. Em decorrência, o maior número de pesquisas volta-se para questões e temas diretamente relacionados e intrínsecos à área de conhecimento específica. Algumas se voltam a questões conceituais da área imbricadas a um modo de ser professor: aprendizagem por mudança conceitual na perspectiva do professor como prático reflexivo, na disciplina Prática de Ensino de Ciências; evolução das concepções sobre ensino, aprendizagem e prática, na disciplina Prática de Ensino de Física; análise da contribuição da refle-

${ }^{5}$ Conforme se poderá observar, as pesquisas poderiam ser organizadas de outras formas. Por exemplo, os estudos sobre a escola normal, o curso de Pedagogia e o Cefam poderiam ser agrupados, juntamente com as licenciaturas, no conjunto dos estudos sobre formação inicial, assim como os estudos sobre a formação do professor de ensino superior e o Cefam também poderiam ser organizados no grupo dos estudos sobre formação contínua. A opção neste estudo relaciona-se ao interesse das autoras em focalizar a atenção em temáticas emergentes da pesquisa em didática e formação de professores, relacionadas às práticas de ensino, às didáticas específicas, ao curso de Pedagogia e à docência no ensino superior. 
xão distanciada na aprendizagem da docência no contexto de disciplina de caráter teórico-metodológico (ensino de matemática) em curso de formação inicial.

Outras estudam a trajetória e análise de propostas da disciplina: $o$ estudo da trajetória da disciplina prática de ensino de inglês; divulgação e aplicação de proposta de ensino de ciências para as séries iniciais; formulação de subsídios para o aperfeiçoamento da disciplina prática de ensino de geografia; relato de experiência do colégio de aplicação na formação de professores de francês; avaliação da formação proporcionada pela licenciatura em Matemática.

Observa-se também a existência de pesquisas preocupadas em examinar a disciplina em contextos escolares e organizacionais, trazendo contribuição para outras áreas: estudo sobre o papel da pesquisa-ação como alternativa metodológica de aprendizagem da docência e parceria universidadel rede de ensino; ou trazendo contribuições de outras áreas, como: apresentação de elementos teóricos para a formação do professor na perspectiva histórico-cultural (MARX, GRAMSCI e VYGOTSKY); avaliação das relações entre ciência, tecnologia e sociedade nas mudanças curriculares e na formação de professores; estudo da relação teoria-prática na disciplina prática de Ensino de História e Ciências Sociais.

Nas pesquisas sobre Formação contínua (11), os temas mais estudados giram em torno da análise de projetos, propostas, experiências e cursos de formação de docentes em serviço. Alguns se configuram como projetos de pesquisa com intervenção numa dada realidade: a vivência de um projeto de investigação-ação desenvolvido por um grupo de professores de ciências naturais; um projeto de formação em serviço na abordagem reflexiva; um curso de formação contínua de professores de educação infantil com ênfase nos aspectos como motricidade, afetividade, consciência corporal; a formação do professor leigo de creches como educador reflexivo; as práticas de formação continuada para a construção de novas relações no cotidiano escolar; a formação do educador de creche na dinâmica de um projeto educacional; uma proposta de aperfeiçoamento de professores de Física baseada em atividades centradas na elaboração de um planejamento didático e na reflexão sobre a prática.

Outros se configuram como análise de processos de formação contínua: a caracterização de um curso a distância para mudar a prática docente; a influência de curso de atualização sobre concepções de fazer ciência e ensinar ciência de professores. Nesse conjunto, há ainda um estudo das representações de coordenadores pedagógicos sobre formação contínua de educado- 
res e outro sobre o jogo como componente da formação inicial e continuada de professores de educação especial.

Ao analisar os dados relativos aos estudos sobre a Escola normal (7), observa-se uma heterogeneidade de temáticas e propósitos, com estudos sobre: os aspectos culturais e do imaginário nas práticas docentes; as questões de gênero na formação de professores; a mediação docente no desenvolvimento de uma pedagogia crítica que incorpora as mídias; o perfil das alunas do curso de Magistério; a aprendizagem da leitura e da escrita na disciplina Conteúdo e Metodologia de Língua Portuguesa do curso de Magistério.

Já os trabalhos que investigaram o Centro de Formação e Aperfeiçoamento do Magistério - Cefam - (5), voltam-se à compreensão dos processos de implantação de um novo projeto de política de formação: o projeto Cefam $e$ as dificuldades de sua implantação; suas dimensões institucionais, pedagógicas, históricas, filosóficas, epistemológicas. Observa-se também estudos apontando novas possibilidades para a ação docente e para os currículos de formação de professores, decorrentes do Projeto Cefam: significado da ação docente entre professores do projeto numa abordagem etnográfica; a prática de estágio e a relação entre teoria e prática na formação de professores.

Os estudos sobre o curso de Pedagogia (3) analisaram: as vivências e concepções das alunas; a evolução do curso como formador de profissionais da educação; as possibilidades do pedagogo para ensinar ciências nas séries iniciais. O número reduzido dessas pesquisas contrasta com o imenso e acalorado debate de que o mesmo vinha sendo objeto na década de 1990.

Das cinco pesquisas sobre Formação do professor do ensino superior, três estudaram as possibilidades da disciplina Metodologia do Ensino Superior na formação para a docência universitária. Os outros dois estudos analisaram a prática docente do professor de Física do Ensino Superior e a prática docente em face das novas tecnologias na universidade.

\section{As pesquisas sobre o professor - temáticas e propósitos}

O quadro II apresenta a organização das pesquisas sobre o professor (44) de acordo com quatro grandes abordagens temáticas e metodológicas apresentadas nos resumos. 
QUADRO II - PESQUISAS SOBRE FORMAÇÃO DE PROFESSORES E ESTUDOS SOBRE O PROFESSOR - 1990-1998 (44 PESQUISAS)

\begin{tabular}{|c|c|c|c|}
\hline Temas & Subtemas/Propósitos & $\begin{array}{l}\text { Metodologia/ } \\
\text { Procedimentos }\end{array}$ & Resultados/Conclusões \\
\hline $\begin{array}{l}\text { Pesquis as } \\
\text { sobre o pen- } \\
\text { samento a a } \\
\text { história do } \\
\text { professor } \\
\text { Mestrado (9) } \\
\text { Dout. (8) } \\
\text { Liv.-Doc. } \\
(3) \\
\text { Total (20) }\end{array}$ & $\begin{array}{l}\text {-Levantamento de con- } \\
\text { cepções/representações } \\
\text { de professores sobre: 1) } \\
\text { ensino; 2) temática } \\
\text { ambiental; 3) conheci- } \\
\text { mento científico; 4) papel } \\
\text { das brincadeiras na edu- } \\
\text { cação infantil; 5) saberes } \\
\text { essenciais do educador } \\
\text { infantil; 6) inovações no } \\
\text { ensino de ciências; 7) re- } \\
\text { lação entre arte e ambien- } \\
\text { te; 8) deficiência escolar, } \\
\text { doença, anomalidade; 9) } \\
\text { corpo de professoras de } \\
\text { pré-escola; } \\
\text {-Estudo sobre a produção } \\
\text { e circulação dos saberes } \\
\text { pedagógicos; } \\
\text {-Investigação, através de } \\
\text { abordagem autobiográfi- } \\
\text { ca, de valores e represen- } \\
\text { tações para a escolha da } \\
\text { profissão professor; } \\
\text {-Concepções de mães e } \\
\text { professores sobre o porta- } \\
\text { dor de síndrome de } \\
\text { Down; } \\
\text {-Estudo sobre o processo } \\
\text { de construção de conhe- } \\
\text { cimento do professor so- } \\
\text { bre o ensino; } \\
\text {-Análise da produção aca- } \\
\text { dêmica sobre professores } \\
\text { primários; } \\
\text {-Análise de história de } \\
\text { vida dos professores; } \\
\text {-Análise das práticas es- } \\
\text { colares e das representa- } \\
\text { ções dos professores so- } \\
\text { bre suas histórias; } \\
\text {-Estudo sobre habilidades } \\
\text { dos professores para atuar } \\
\text { na educação especial; }\end{array}$ & $\begin{array}{l}\text {-Análise de discurso (1); } \\
\text {-Estudo de um caso (2); } \\
\text {-Análise de narrativas } \\
(1) ; \\
\text {-História oral (1); } \\
\text {-Pesquisa teórica (1); } \\
\text {-Análise de discursos e } \\
\text { de práticas (1); } \\
\text {-Levantamento/entrevis- } \\
\text { tas (4); } \\
\text {-Levantamento/entrevis- } \\
\text { tas e observação de reu- } \\
\text { niões (1); } \\
\text {-Levantamento/entrevis- } \\
\text { tas e observação de au- } \\
\text { las (1); } \\
\text {-Pesquisa etnográfica } \\
\text { (1); } \\
\text {-Análise de } 4 \text { romances } \\
\text { escritos por professores } \\
\text { (1); } \\
\text {-Análise de escritos da } \\
\text { produção acadêmica (1); } \\
\text {-Análise de textos auto- } \\
\text { biográficos (1); } \\
\text {-Sem informações sufici- } \\
\text { entes sobre metodologia } \\
\text { (3); }\end{array}$ & $\begin{array}{l}\text {-Explicação das causas que jus- } \\
\text { tificam a resistência do professor } \\
\text { para lidar com conteúdos de ori- } \\
\text { gem científica; } \\
\text {-Explicação das concepções dos } \\
\text { professores como elementos cen- } \\
\text { trais em processos de mudanças } \\
\text { e inovações; } \\
\text {-Representações sobre corpo in- } \\
\text { terferem nas práticas e vivências } \\
\text { dos professores; } \\
\text {-Importância de se considerar as } \\
\text { representações dos professores } \\
\text { em seu processo de construção de } \\
\text { conhecimentos; } \\
\text {-Importância de se considerar as } \\
\text { determinações da história de vida } \\
\text { (influenciadas por questões de } \\
\text { classe e gênero) para a compre- } \\
\text { ensão da profissão professor; } \\
\text {-Definição da didática como ini- } \\
\text { ciação e potencial do uso de rela- } \\
\text { tos autobiográficos na formação } \\
\text { de professores; } \\
\text {-Constatação da necessidade de } \\
\text { atenção à família do portador de } \\
\text { síndrome de Down e práticas pe- } \\
\text { dagógicas respeitando as dificul- } \\
\text { dades constatadas pelos alunos; } \\
\text {-Caracterização das habilidades } \\
\text { dos professores para atuar na edu- } \\
\text { cação especial; } \\
\text {-Caracterização dos saberes es- } \\
\text { senciais para atuar na educação } \\
\text { infantil; } \\
\text {-Explicações sobre as implica- } \\
\text { ções das concepções dos profes- } \\
\text { sores em suas práticas; } \\
\text {-Denúncia da estigmatização dos } \\
\text { seres humanos como incapazes e } \\
\text { improdutivos a partir da análise } \\
\text { das representações de deficiência; }\end{array}$ \\
\hline
\end{tabular}




\begin{tabular}{|c|c|c|c|}
\hline & $\begin{array}{l}\text {-Estudo de narrativas de } \\
\text { uma professora; } \\
\text {-Estudo da resistência do } \\
\text { professor à mudança (ên- } \\
\text { fase: incorporação das } \\
\text { tecnologias da comunica- } \\
\text { ção na escola); } \\
\text {-Análise da história de } \\
\text { vida de professores de } \\
\text { deficientes mentais; }\end{array}$ & & \\
\hline $\begin{array}{l}\text { Investiga- } \\
\text { ções sobre } \\
\text { que s tõe s } \\
\text { políticas e } \\
\text { profissio- } \\
\text { nais do } \\
\text { ex ercício } \\
\text { da profis- } \\
\text { são docente } \\
\text { Dout. (4) }\end{array}$ & $\begin{array}{l}\text {-Análise do professor } \\
\text { como pertencente a uma } \\
\text { classe social; } \\
\text {-Estudo dos aspectos po- } \\
\text { líticos da profissão docen- } \\
\text { te; } \\
\text {-Análise da crise e esgo- } \\
\text { tamento do movimento } \\
\text { dos professores na transi- } \\
\text { ção democrática; } \\
\text {-Estudo do movimento } \\
\text { dos professores indígenas } \\
\text { a partir de seus encontros } \\
\text { anuais; } \\
\text {-Análises da história do } \\
\text { Centro Professorado } \\
\text { Paulista (movimento de } \\
\text { reorganização do magis- } \\
\text { tério); }\end{array}$ & $\begin{array}{l}\text {-Pesquisa teórica (1); } \\
\text {-Análise documental } \\
(1) ; \\
\text {-Sem informações sufici- } \\
\text { entes sobre metodologia } \\
(2) ;\end{array}$ & $\begin{array}{l}\text {-Importância de se considerar as } \\
\text { determinações de classe nos cur- } \\
\text { sos de formação de professores; } \\
\text {-Análise da crise e esgotamento } \\
\text { do movimento dos professores na } \\
\text { transição democrática; } \\
\text {-Reflexão sobre a concepção de } \\
\text { escola para índios nos encontros } \\
\text { anuais de professores indígenas; } \\
\text {-Análise da história do Centro } \\
\text { Professorado Paulista (movimen- } \\
\text { to de reorganização do magisté- } \\
\text { rio); }\end{array}$ \\
\hline $\begin{array}{l}\text { Pe squi is as } \\
\text { sobre a práti- } \\
\text { ca, a didática } \\
\text { e o trabalho } \\
\text { dos profes- } \\
\text { sores }\end{array}$ & $\begin{array}{l}\text {-Análise de prática peda- } \\
\text { gógica de professor de 5. } \\
\text { série; } \\
\text {-Estudos da prática peda- } \\
\text { gógica dos professores } \\
\text { alfabetizadores; } \\
\text {-Relato autobiográfico de } \\
\text { práticas de alfabetização; } \\
\text {-Análise das causas do } \\
\text { sofrimento dos professo- } \\
\text { res de Educação Física; } \\
\text {-Análise das dificuldades } \\
\text { dos professores inician- } \\
\text { tes; } \\
\text {-Análise de um processo } \\
\text { coletivo de pesquisa-ensi- } \\
\text { no de professores que } \\
\text { problematizam a prática, } \\
\text { analisam-na criticamente } \\
\text { e propõem novas práticas; }\end{array}$ & $\begin{array}{l}\text {-Pesquisa etnográfica } \\
(2) ; \\
\text {-Estudo de um caso (1); } \\
\text {-Análise de prática peda- } \\
\text { gógica (3); } \\
\text {-Levantamento/entrevis- } \\
\text { tas (2); } \\
\text {-Relato da própria práti- } \\
\text { ca como professor alfa- } \\
\text { betizador (1); } \\
\text {-Análise documental, } \\
\text { observação participante } \\
\text { e entrevista (1); } \\
\text {-Sem informações sufici- } \\
\text { entes sobre metodologia } \\
\text { (4); }\end{array}$ & $\begin{array}{l}\text {-Conhecimento sobre prática } \\
\text { pedagógica: a) constatação de } \\
\text { que o ensino centra-se na maté- } \\
\text { ria; b) disciplina e avaliação } \\
\text { como núcleos simbólicos do tra- } \\
\text { balho docente; c) isolamento e } \\
\text { impotência dos professores; d) a } \\
\text { formação é um processo pessoal; } \\
\text { e) importância de se considerar o } \\
\text { saber-fazer do professor como } \\
\text { elemento de reflexão crítica nos } \\
\text { cursos de formação de professo- } \\
\text { res; f) compreensão da sala de } \\
\text { aula como espaço não só de re- } \\
\text { produção, mas de transformação; } \\
\text { h) potencial das práticas reflexi- } \\
\text { vas na tomada de consciência e } \\
\text { re-significação das relações de } \\
\text { ensino; }\end{array}$ \\
\hline
\end{tabular}


-Investigação etnográfica sobre a prática de uma professora considerada eficiente e bem-sucedida; -Análise dos caminhos que professores encontram para desenvolver projetos pedagógicos telemáticos (novas tecnologias);

-Estudo do desenvolvimento do processo reflexivo de uma professora de educação infantil em prática de leitura/contagem de histórias;

-Estudo sobre alunos de cinco professoras de Didática e Prática de Ensino consideradas bemsucedidas;

-Análise do papel do professor coordenador na melhoria da qualidade do ensino;

-Análise do comportamento de professores de Português diante de metas educacionais;
-Contribuições para a didática: a) importância de se considerar a pesquisa no ensino; b) compreensão da didática como expressão da prática dos professores; c) importância da convivência de alunos em formação com bons professores;

-Contribuições para a formação contínua: Constatação da importância da formação em serviço na melhoria da qualidade de ensino;

- Conhecimento sobre prática pedagógica de professores iniciantes: a) a formação de professores poderia ser aprimorada se grande parte das dificuldades apontadas pelos professores iniciantes fossem incorporadas nos cursos e abordadas de maneira ativa e reflexiva; $b$ ) potencialidades do curso de Didática na antecipação de problemas dos professores iniciantes;

-Conhecimento sobre práticas pedagógicas com novas tecnologias:

demonstração da possibilidade de integração de tecnologias e educação quando os professores atuam juntos;

-Conhecimento sobre condições de exercício da profissão: a) falta de recursos e condições materiais para exercer a docência geram insatisfação, sentimento de culpa e indignidade, com consequiências para o ensino;

-Apresentação de sugestões para a efetivação de metas educacionais;

Trabalhos -Estudo do processo de -Estudo de caso do tipo -As práticas femininas doméstisobre iden- construção da identidade tidade pro- dos profissionais de crefissional e ches; etnográfico (1); -Pesquisa etnográfica $(1)$ cas são componentes fundamentais na construção da identidade profissional das mulheres que trabalham em creches; 


\begin{tabular}{|c|c|c|c|}
\hline $\begin{array}{l}\text { Mestrado } \\
(1) \\
\text { Dout. (3) } \\
\text { Total (4) }\end{array}$ & $\begin{array}{l}\text {-Estudo da história da for- } \\
\text { mação profissional das } \\
\text { mulheres professoras; } \\
\text {-Interpretação do trabalho } \\
\text { docente nas séries iniciais } \\
\text { a partir do conceito de } \\
\text { cuidado infantil (ênfase: } \\
\text { gênero e idade); } \\
\text {-Estudo sobre as concep- } \\
\text { ções de feminino e mas- } \\
\text { culino dos professores; }\end{array}$ & $\begin{array}{l}\text {-Sem informações sufici- } \\
\text { entes sobre metodologia } \\
(2) ;\end{array}$ & $\begin{array}{l}\text {-Presença marcante do "cuidado" } \\
\text { nos ideais e práticas pedagógicas; } \\
\text {-O gênero é um elemento consti- } \\
\text { tuinte das percepções de profes- } \\
\text { sores(as) sobre a escola, os alu- } \\
\text { nos e a relação escola-sociedade; }\end{array}$ \\
\hline
\end{tabular}

No primeiro conjunto estão reunidos os estudos sobre o pensamento e a história do professor (20). No segundo encontram-se as investigações sobre questões políticas e profissionais do exercício da profissão docente (04). O terceiro contempla pesquisas sobre a prática, a didática e o trabalho dos professores (14). No quarto grupo estão os trabalhos sobre questões de gênero e identidade profissional (04).

As pesquisas sobre o pensamento e a história do professor (20) contemplam estudos que, de alguma forma, buscam compreender e/ou explicar as concepções, as representações, os saberes, as razões da ação docente, os valores, as crenças, as habilidades e a história do professor. Para tanto, realizam levantamento de concepções e representações de professores sobre conceitos, questões e temas pertinentes ao exercício da docência em diversos âmbitos e níveis de ensino. São eles: temática ambiental, ensino, conhecimento científico, papel das brincadeiras na educação infantil, saberes essenciais do educador infantil, inovações no ensino de ciências, relação entre arte e ambiente, deficiência escolar, doença, anormalidade, corpo.

O conjunto de pesquisas também inclui estudos sobre: a produção e circulação dos saberes pedagógicos; os valores e as representações envolvidos na escolha da profissão professor (por meio de abordagem autobiográfica); as concepções de mães e professores sobre o portador de síndrome de Down; o processo de construção de conhecimentos do professor sobre o ensino; a produção acadêmica sobre professores primários; a história de vida dos professores; as práticas escolares e das representações dos professores sobre suas histórias; as habilidades dos professores para atuar na educação especial; as narrativas de uma professora; a resistência do professor à mudança e ao uso das tecnologias da comunicação na escola; a história de vida de professores de deficientes mentais. 
As pesquisas sobre questões políticas e profissionais do exercício da profissão docente (4) focalizam a figura do professor no contexto social mais amplo e as implicações daí decorrentes em termos profissionais e sociais. Nesse sentido, esses estudos contemplam análises sobre: o professor como pertencente a uma classe social; os aspectos políticos da profissão docente; a crise e esgotamento do movimento dos professores na transição democrática; o movimento dos professores indígenas a partir de seus encontros anuais; a história do Centro Professorado Paulista (movimento de reorganização do magistério).

As pesquisas sobre a prática, a didática e o trabalho dos professores (14) realizam análises sobre: a prática pedagógica de um professor de 5. ${ }^{a}$ série; a prática pedagógica de professores alfabetizadores; as causas do sofrimento dos professores de Educação Física; as dificuldades dos professores iniciantes; um processo coletivo de pesquisa-ensino de professores que problematizam a prática e realizam mudanças em seu trabalho; a prática de uma professora considerada eficiente e bem-sucedida (investigação etnográfica); os caminhos que professores encontram para desenvolver projetos pedagógicos telemáticos (novas tecnologias); o desenvolvimento do processo reflexivo de uma professora de educação infantil em prática de leitura/ contagem de histórias; a aprendizagem de alunos de professoras de Didática e Prática de Ensino consideradas bem-sucedidas; o papel do professor coordenador na melhoria da qualidade do ensino; o comportamento de professores de Português diante de metas educacionais.

As pesquisas sobre identidade profissional e questões de gênero (4) contemplam explicações e análises sobre: o processo de construção da identidade dos profissionais de creches; a história da formação profissional das mulheres professoras; o trabalho docente nas séries iniciais a partir do conceito de cuidado infantil (ênfase: gênero e idade); as concepções de feminino e masculino dos professores.

\section{Contribuições das pesquisas para a produção de conhecimento sobre o professor, a sua formação e o campo da didática}

Uma análise das principais temáticas e propósitos das pesquisas em relação aos seus resultados e conclusões (conferir anexos I e II) revela a 
multiplicidade de abordagens e perspectivas que a compreensão do exercício da docência e da formação de professores requer. Diversas linhas teóricas e metodológicas foram mobilizadas nas pesquisas para a compreensão desse objeto.

Examinando as pesquisas sobre formação de professores e os estudos sobre o professor alguns aspectos comuns se sobressaem. No que diz respeito à forma de abordagem da temática, percebe-se que os estudos podem até partir das dificuldades e dos dilemas da educação e da formação docente, mas não se limitam à denúncia da existência desses problemas. Em geral, os trabalhos colocam em análise projetos, propostas e alternativas teóricas e metodológicas para a formação docente. Nesse aspecto, a proposta de formação reflexiva de professores ou pelo menos a consideração da necessidade da reflexão como componente da formação aparece em destaque nos trabalhos analisados, especialmente nos referentes às licenciaturas e à formação continuada.

Outro elemento importante a ser considerado diz respeito ao fato de os autores dos estudos serem profissionais da formação, cuja disciplina, curso ou programa em que atuam tornou-se objeto de suas investigações. Isso explica, em parte, a ênfase das pesquisas das licenciaturas nas práticas de ensino e das pesquisas sobre formação continuada com a análise de projetos, propostas e experiências de cursos de formação em serviço. E coloca a necessidade de se buscar um conhecimento mais abrangente sobre o tema de tal forma que, a partir dos resultados dos estudos de caráter mais pontual, possibilite a afirmação de consensos provisórios sobre os professores e sua formação, tendo em vista contribuir com a formulação de políticas para a área.

Quanto ao universo de questões das pesquisas sobre formação de professores, destaca-se a preocupação em analisar se e como os processos formativos alteram concepções e conceitos dos professores em formação. Essa preocupação também se verifica na maior parte dos estudos sobre o professor que, em grande parte, levantam concepções e representações sobre conceitos pertinentes à docência. $\mathrm{O}$ que poderia indicar uma tendência das pesquisas analisadas em investir na compreensão do pensamento do professor, com semelhanças com uma linha de pesquisa denominada paradigma do pensamento do professor, que tem sido veiculada em alguma literatura sobre formação de professores (ZABALZA, 1994; GARCIA, 1995).

Esse paradigma de investigação baseia-se no pressuposto de que os professores são profissionais racionais e que, enquanto tais, têm sua atuação dirigida por seus pensamentos (juízos, crenças, teorias implícitas etc). Essas idéias, que por óbvias demais, causam espanto quando apresentadas como 
paradigma, conduzem às seguintes orientações metodológicas: 1) compreender a conduta explícita dos professores implica ter acesso ao seu campo de referências cognitivas e de significados, desde o momento em que o professor as realiza; requer, portanto, conhecer quais são os pensamentos do professor relacionados com suas ações; 2) entender o professor como profissional racional, que sabe o que faz porque pensa a sua ação, pressupõe que ele, melhor que ninguém, pode esclarecer o porquê das suas ações. Em poucas palavras, pressupõe aceitar perguntar-lhe por que é que faz as coisas pode ser um bom método para saber realmente porque é que as faz. (ZABALZA, 1994, p. 34).

Até o momento, o estudo realizado não nos permite afirmar se as pesquisas analisadas, especialmente os que levantaram concepções e representações de professores, pautaram-se por essas orientações metodológicas e se filiam a esse paradigma. No entanto, as semelhanças possibilitam procederse a uma aproximação com a perspectiva representada pelo autor citado.

Ainda quanto às questões que motivaram a realização do conjunto analisado das pesquisas sobre formação de professores, destaca-se a permanência de temas recorrentes nos cursos de formação de professores, como o papel do estágio, a relação teoria e prática, o aprofundamento de conceitos teóricos pertinentes à docência, as questões de gênero (docência como profissão feminina) e a busca pela melhoria das práticas de ensino. Destaca-se também a análise e proposição de alternativas metodológicas para a formação, como, por exemplo, as que fazem uso da pesquisa-ação como recurso de aprendizagem da docência e as que investigam inclusão das novas tecnologias e a educação a distância no trabalho e na formação docente.

Quanto aos estudos sobre o professor, além da forte preocupação com temáticas relacionadas ao pensamento e à história dos professores, verificase uma ênfase em questões da prática, da didática e do trabalho dos professores com o ensino, ao lado das investigações sobre questões políticas, profissionais e de gênero.

\section{Consensos possíveis}

Sem esgotar a análise, é possível anunciar alguns consensos provisórios. As pesquisas que colocaram sob análise a formação realizada em disci- 
plinas, cursos, programas e projetos confirmam as possibilidades da formação na transformação das concepções ou representação dos professores, indicando a necessidade de se continuar investindo nessa linha de estudos, tendo em vista compreender, por exemplo, quais as ressonâncias das mudanças de concepções nas práticas docentes. Os resultados dos estudos também reafirmam o potencial de processos que têm a reflexão como componente da formação na produção do conhecimento dos professores sobre seu trabalho.

As pesquisas sobre o pensamento e a história dos professores indicam a importância de se considerar as concepções e representações como elementos centrais do processo de construção de conhecimentos dos professores. Indicam, também, a necessidade de se considerar as determinações da história de vida (influenciadas por questões de gênero e classe social) na compreensão da profissão docente.

Outras contribuições importantes dos trabalhos analisados que merecem destaque pelos subsídios que podem fornecer à melhoria da formação docente dizem respeito à produção de conhecimento sobre:

- aprender da profissão: o professor aprende a ser professor desde quando ingressa na escola, na condição de aluno; o saber que o professor constrói na formação é ético e estético;

- formação de professores e novas tecnologias: importância de se considerar a mediação docente na educação das crianças em face às mídias; cursos estruturados em função da lógica do conhecimento sistematizado não bastam para mudar a prática docente; é necessário explicitar a relação entre teoria e prática nesses cursos. É necessário construir um modelo de educação a distância para formação de professores, sendo que já existem propostas nessa direção.

- formação contínua: a) tendência de considerar a formação como um continnum; b) e a escola como locus privilegiado da formação; c) o potencial da colaboração reflexiva na transformação da cultura escolar; d) importância de se considerar aspectos como motricidade, consciência corporal, afetividade etc. na formação de professores de educação infantil; e) importância de se compreender a prática dos professores para implementar processos de formação continuada; f) constatação da importância da formação em serviço na melhoria da qualidade de ensino;

- formação de professores para atuar na educação especial: a) uma escola inclusiva requer uma nova pedagogia e novos professores; 0 
conhecimento das possibilidades do jogo é fundamental na formação de educadores para atuar na escola inclusiva;

- formação de professores para a educação infantil: a) potencial da abordagem reflexiva; b) importância de se considerar o projeto educacional na formação do educador de creche;

- formação de professores e gênero: a produção sobre formação de professores (magistério) não considera o referencial gênero;

- papel dos estágios: a) possibilidades da pesquisa acadêmica na transformação da prática; b) necessidade de se acompanhar o estágio nos processos de formação;

- formação do professor do ensino superior: apesar de não possuir referencial teórico próprio, a metodologia do ensino superior pode se constituir em campo específico de conhecimentos; caracterização da prática docente no ensino superior; fornecimento de subsídios para a formação contínua de professores de Física e reconhecimento do papel da prática reflexiva na tomada de consciência do processo de ensino e aprendizagem; fornecimento de subsídios para a reflexão sobre prática docente na universidade, a partir de um protótipo parcial de um sistema de educação a distância;

- questões políticas e profissionais do exercício da profissão docente: necessidade de se considerar as determinações de classe nos cursos de formação de professores;

- prática pedagógica: a) constatação de que o ensino centra-se na matéria; b) disciplina e avaliação como núcleos simbólicos do trabalho docente; c) isolamento e impotência dos professores; d) a formação é um processo pessoal; e) importância de se considerar o saber-fazer do professor como elemento de reflexão crítica nos cursos de formação de professores; f) compreensão da sala de aula como espaço não só de reprodução, mas de transformação; h) potencial das práticas reflexivas na tomada de consciência e re-significação das relações de ensino;

- prática pedagógica de professores iniciantes: a) a formação de professores poderia ser aprimorada se grande parte das dificuldades apontadas pelos professores iniciantes fossem incorporadas nos cursos e abordadas de maneira ativa e reflexiva; b) potencialidades do curso de didática na antecipação de problemas dos professores iniciantes;

- contribuições para a didática: a) importância de se considerar a pesquisa no ensino; b) compreensão da didática como expressão da 
prática dos professores; c) importância da convivência de alunos em formação com bons professores;

- condições de exercício da profissão: a) falta de recursos e condições materiais para exercer a docência geram insatisfação, sentimento de culpa e indignidade, com consequiências para o ensino;

- identidade profissional e questões de gênero: as práticas femininas domésticas são componentes fundamentais na construção da identidade profissional das mulheres que trabalham em creches; presença marcante do "cuidado" nos ideais e práticas pedagógicas; o gênero é um elemento constituinte das percepções de professores(as) sobre a escola, os alunos e a relação escola-sociedade.

As análises empreendidas neste estudo confirmam o pressuposto que orientou a sua realização. O de que compreensão do exercício da docência e da formação de professores requer aportes de várias áreas, numa abordagem multirreferencial (ARDOÍNO, 1992) e uma postura investigativa que assuma plenamente a complexidade da realidade sobre a qual se interroga e possibilite uma leitura plural da realidade, sob diferentes ângulos e perspectivas que não sejam, necessariamente, excludentes.

\section{Contribuições dos trabalhos analisados para a construção de metodologias de pesquisa sobre formação de professores}

Por um exame do item nas tabelas I e II, pode-se perceber uma certa dificuldade em identificar claramente o caminho percorrido nas pesquisas para o alcance de seus propósitos. Essa dificuldade tanto pode ser atribuída a questões de natureza conceitual sobre metodologia de pesquisa em educação, cuja discussão extrapolaria os limites deste texto, quanto à falta de informações mais precisas nos resumos analisados. Em vista disso, optou-se por enfatizar as técnicas de coleta de dados explicitamente mencionadas pelos autores a partir de uma categorização formulada por ANDRÉ (2000) quando analisou os principais tipos de pesquisas sobre formação de professores no Brasil.

Uma primeira constatação sobre as metodologias mais utilizadas nos estudos em geral confirma a presença de procedimentos metodológicos convencionais da pesquisa sobre ensino: estudos de um caso, levantamento de dados por meio de questionários e entrevistas, análise de prática pedagógica, 
análise documental, bem como pesquisas de natureza teórica ${ }^{6}$, pesquisas etnográficas, dentre outros. Esses procedimentos aparecem em todos os agrupamentos de pesquisas sobre formação de professores e nos estudos sobre o professor. Em vista disso, serão apresentadas as tendências marcantes de cada um dos conjuntos de pesquisas, deixando-se de mencionar esses procedimentos.

Nas pesquisas sobre formação de professores, entre os procedimentos mais utilizados para os estudos que focalizaram as licenciaturas, destaca-se a análise de situações reais de aprendizagem da docência/disciplina prática de ensino, em função da preocupação de boa parte das pesquisas com o papel da prática de ensino na formação. Nos estudos que enfatizaram a formação contínua, a escola normal e o Cefam, observa-se uma variedade de procedimentos metodológicos, mas há ligeira predominância da análise de experiências e projetos e da pesquisa-ação.

Nos trabalhos voltados para o pensamento e a história do professor, há uma predominância de estudos que realizam levantamento de concepções, representações, opiniões etc, combinados a outros procedimentos (como observação de aulas, de reuniões e outros). Também se verifica forte presença de metodologias que, de alguma forma, coletam dados sobre a vida dos professores por meio de instrumentos como: narrativas, história oral, análise de discursos e práticas, romances escritos pelos professores, escritos da produção acadêmica, textos autobiográficos, dentre outros.

Nas pesquisas sobre questões políticas e profissionais do exercício da profissão docente, a ênfase é a pesquisa teórica e a análise documental. Ao contrário, nas pesquisas sobre a prática, didática e trabalho do professor, observam-se a predominância de pesquisas etnográficas, estudos de um caso, relatos de experiências e análise de práticas pedagógicas, ao lado de outros procedimentos. A forte presença de pesquisas etnográficas também se verifica nos estudos sobre identidade profissional e questões de gênero.

A análise das abordagens metodológicas das pesquisas sobre temas correlacionados à formação de professores sugere a consolidação de metodologias e procedimentos construídos a partir das temáticas e propósitos de interesse dos estudos, bem como a emergência de outras abordagens metodológicas, como análise de discursos, narrativas, autobiografias, romances escritos pelos professores, entre outros.

${ }^{6}$ Conforme andré (Op. Cit, p. 93) "nos estudos teóricos enquadram-se os que utilizam categorias amplas, fazem discussões filosóficas, defendem uma determinada posição, com argumentos e fundamentos teóricos". 


\section{REFERÊNCIAS}

ANDRÉ, M. A pesquisa sobre formação de professores no Brasil - 1990-1998. In: CANDAU, Vera. Ensinar e aprender: sujeitos, saberes e pesquisa. Rio de Janeiro: DP\&A, 2000.

ARDOÍNO, J. L'approche multireferentielle (plurielle) des situacions éducatives et formatives - 25 as des Sciences de l'Éducation. Paris: INRP, 1993.

BATTAGLIA, B. B. (Org.). Teses e dissertações defendidas na FEUSP - 1967 a 1998. São Paulo, Feusp, 2003.

GARCIA, C. M. Formação de professores: para uma mudança educativa. Porto: Porto Editora, 1995.

PIMENTA, S. G. O estágio na formação de professores: unidade teoria e prática? São Paulo: Cortez, 2001.

A pesquisa em didática - 1996 a 1999. In: CANDAU, Vera Maria. Didática, currículo e saberes escolares. Rio de Janeiro: DP\&A, 2000.

ZABALZA, M. A. Diários de aula: contributo para o estudo dos dilemas práticos dos professores. Porto: Porto Editora, 1994.

Texto recebido em 09 mar.2004

Texto aprovado em 10 jul. 2004 